\title{
Green and Light Weight Vehicles Power Transmission System Design and Development
}

\author{
Rajesh C V S ${ }^{1}$, P Janardhana Kiran ${ }^{2}$ \\ ${ }^{1,2}$ Assistant Professor in Department of Mechanical Engineering \\ ${ }^{1}$ Vizag Institute of Technology, ${ }^{2}$ Sanketika Vidya Parishad Engineering College, \\ Visakhapatnam, Andhra Pradesh, India
}

\begin{abstract}
The learning on green vehicle was introduced and promoted to reduce the difficulty of air toxic waste caused by emissions of conventional vehicle. The Green mobility are vehicles with low fuel/energy consumption and low/zero exhaust gas emission, these vehicles are like hybrid, battery powered, and fuel cell electric vehicle that can be enhanced to be more efficient than the conventional vehicles through a new design and development of power transmission system. Power transmission system for green and lightweight vehicles consists of different components like gear box, propeller shaft, differential and final drive. In this review more emphasis is given to gear box due to some reasons: firstly, it is one of the heaviest component of the power train system and as a result weight reduction is critically needed to increase the efficiency of the vehicle. Secondly, gearshift takes place therefore, torque interruption needs to minimize. The outcome from the simulation software will be validated by investigational tests on test rigs. One way of minimizing fuel consumption is to reduce the weight of the gearbox by $10 \%$ reduction in vehicle mass can enhanced fuel economy by about to $7 \%$. The dissimilar researchers confirm that to have high vehicle efficiency the type of the transmission they used matters. A vehicle using automated manual transmission (AMT) and dual clutch transmission is more efficient in terms of less energy loss and gearshift comfort.
\end{abstract}

Keywords: Green vehicle, Light weight, Gearshift, Fuel consumption, Power transmission, Clutch.

\section{INTRODUCTION}

Global, regional and local governments are investing heavily in the development of green vehicles like clean electric, hybrid vehicle. Private and government sectors all over the world are searching for technological innovations that reduce costs and increase environment-friendly and low fuel utilization vehicles. Planning on typical weather change have been posing automotive industry challenges, as carmakers have to meet tight emission standards from different countries. Adapting green technologies will have the potential of reducing $\mathrm{C} 02$ emissions by 35 million to 44 million tons from vehicles with IC engine. The cost and green benefit is an optimal solution for technology to improve the fuel efficiency of power transmission by lowering efficiency loss and decreasing drag torque losses in the transmission. Automobile technology has brought advancement and convenience to modem lives, but at the same time lead to serious environmental issues. A countermeasure has evolved to address against such problems, an automotive technology such as highefficiency engine, hybridization, or weight reduction has emerged. In automotive technology, the term power transmission refers to the group of components that uses to transfer power from the engine and deliver it to the road surface, water, or air. The amount of torque energy wasted on an automatic transmission (AT) is due to its slipping nature of the torque converter applied in the widely-used planetary gear-type or continuously variable automatic transmissions. This disadvantage no longer exists when it comes to the manual transmission (MT), in which the engine and the wheels can be mechanically linked by the clutch. To date, electric vehicles (EVs) have employed single speed reduction gears for transmission [21, 22]. However, to meet the required vehicle performance, such as the acceleration performance, the climbing performance and the 
maximum speed, with a single-speed reduction gear, a traction motor with a high power and a high torque capacity is needed, as well as a high-capacity inverter to drive the motor. Expecting to improve the EV performance, researchers and designers are investing much of their resources to the application of multiple speed transmissions instead of traditional single speed transmissions. The detail advantages of two-speed transmission over single speed are demonstrated and reported work. The comparison between IC engine and EV in terms of torque and speed, IC engine is not capable of propelling a vehicle from rest on its own on account of generating low torques at low rpm, a torque amplifying transmission system is very much required, For such vehicles, transmission is also required to allow a vehicle to stop by disconnecting the drive and change the speed ratio between engine and wheels whenever required.

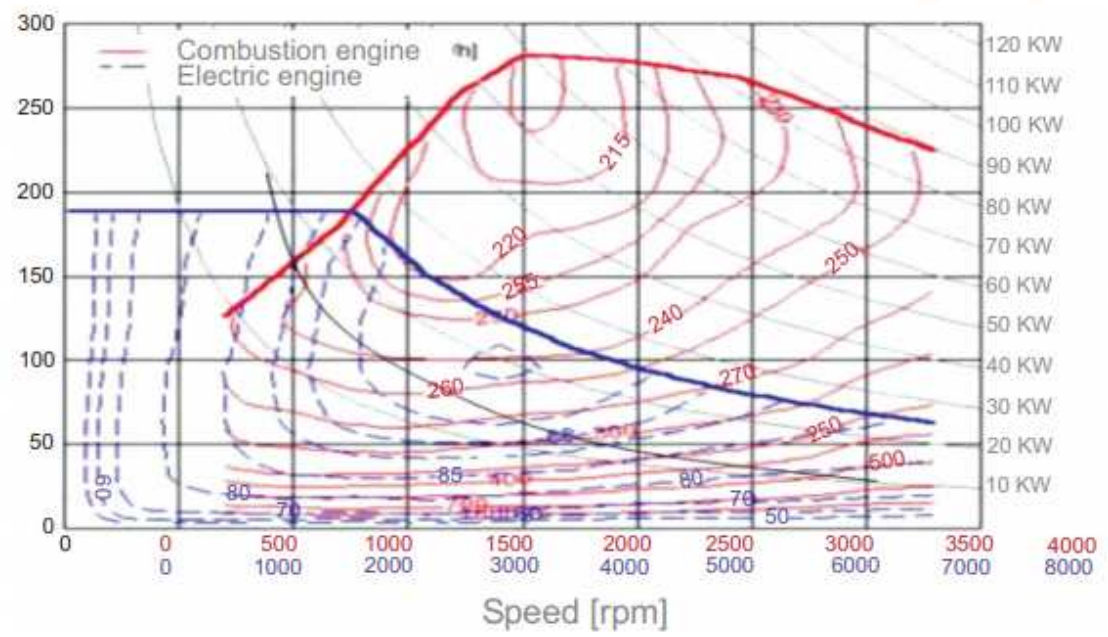

Materials and Methods used:

The recent methodology used for Developing of power transmission system for green vehicles in comparison with conventional vehicle. These days the design and methodology of power transmission system can enhance both in terms of efficiency increment and weight reduction. In order to get the target, showing the methods, how to develop the power transmission system for green and lightweight vehicle, is very crucial.
This Research paper of discuss about numerical and experimental investigation of drag torque in a twospeed dual clutch transmission testing performed using a green vehicle powertrain with a two-speed DCT uses a methodology of Measured input and output parameters like speed and torque and oil temperature of DCT case and test rig operated at stable conditions (gear, speed, motor torque, and oil temp) for at least two minutes.

New Automated Design Process
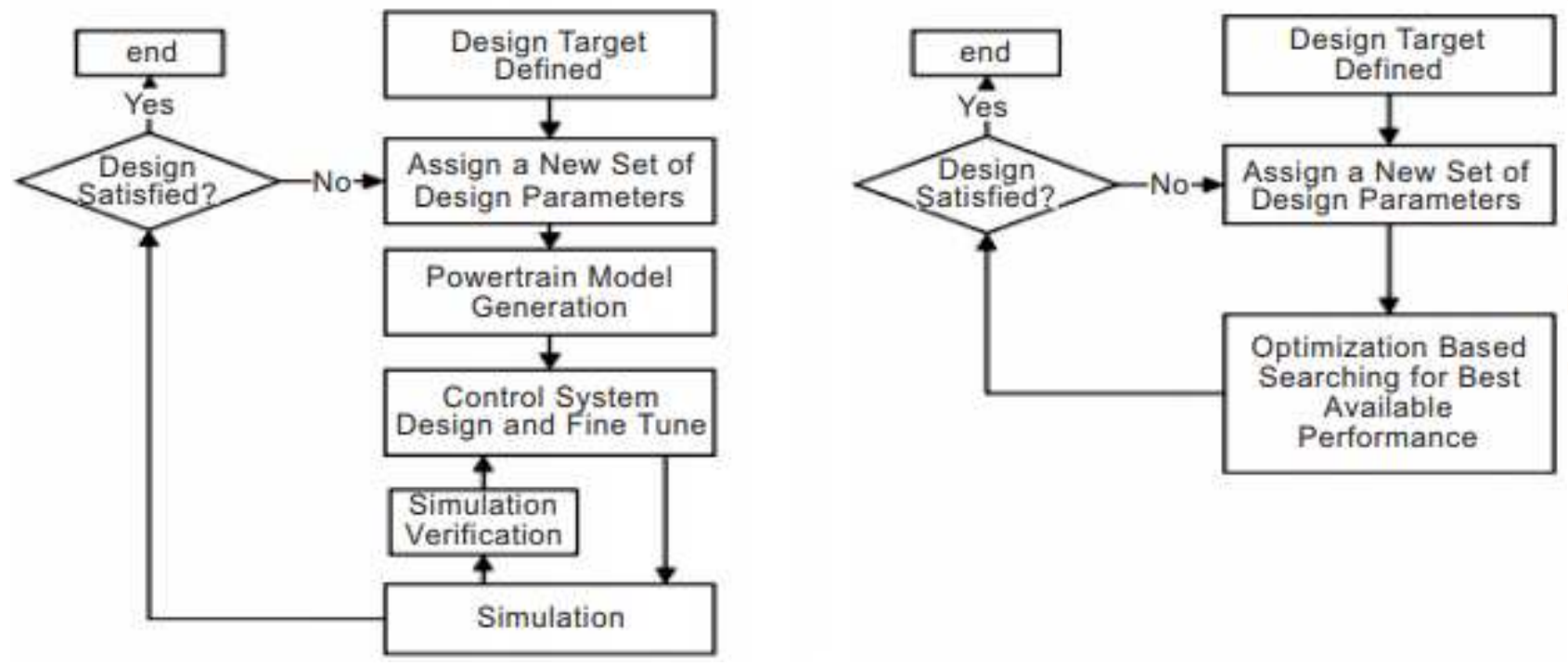

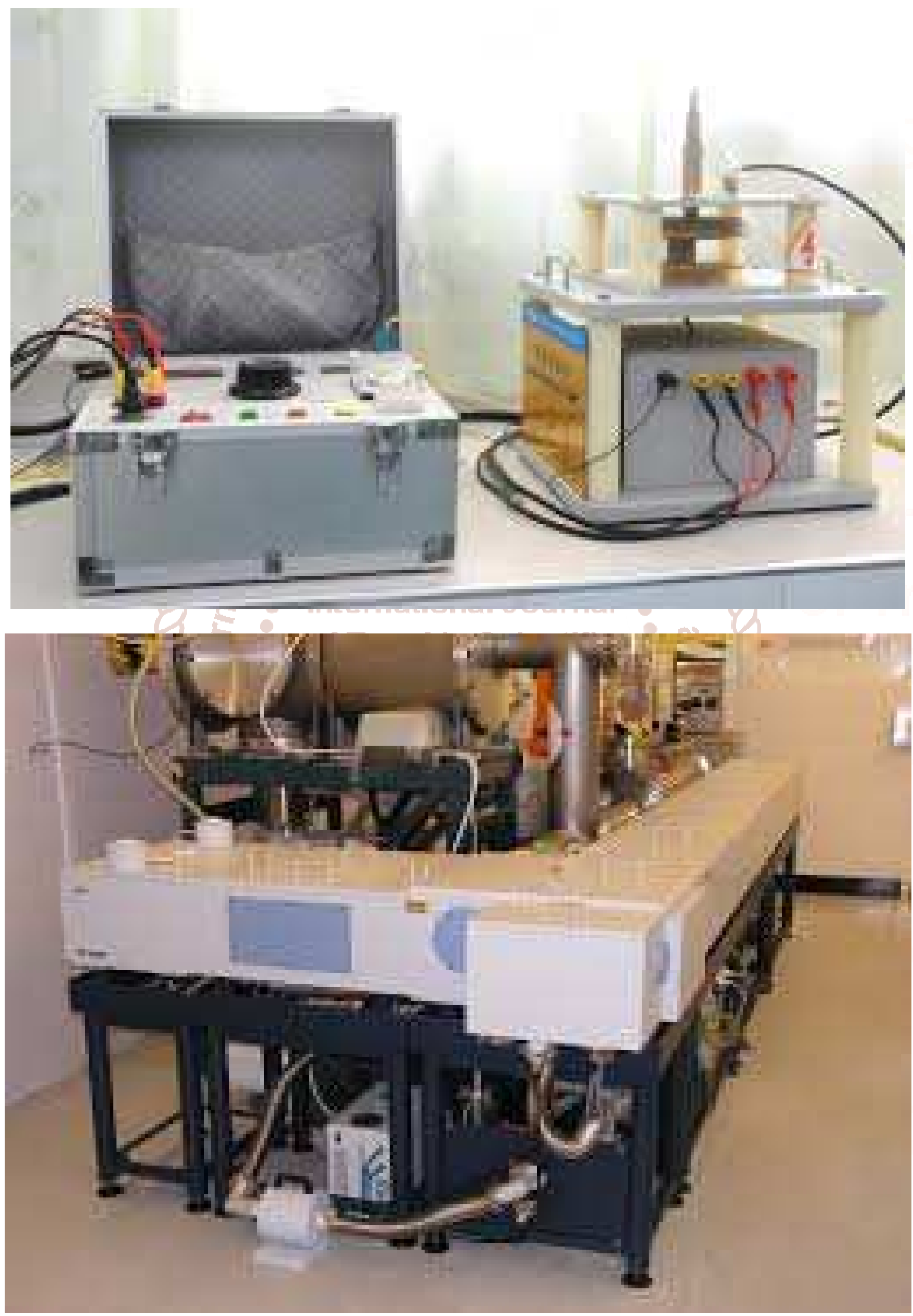


\section{Material Used for Green vehicle Transmission:}

The type of materials used has a significant effect on fuel consumption and weight of vehicles as a result many researchers agree that in every $10 \%$ minimization in vehicle weight can reduce fuel consumption by about $7 \%$ so designer and manufacturers spent more time on searching for materials that have lightweight and can withstand the required load. Power transmission system components comprise the heaviest system on the vehicle; therefore, weight reduction is more feasible in terms of fuel consumption [39].
To date due to environmental issues researchers are giving focus in composite materials due to good mechanical property. Vehicle power transmission components are manufactured from metal matrix composites (MMCs) that use filaments, whiskers or particles of high strength materials to enhance the properties of the base matrix in critical areas. A more ambitious solution is possible in the medium term, using polymer matrix composites (PMCs).

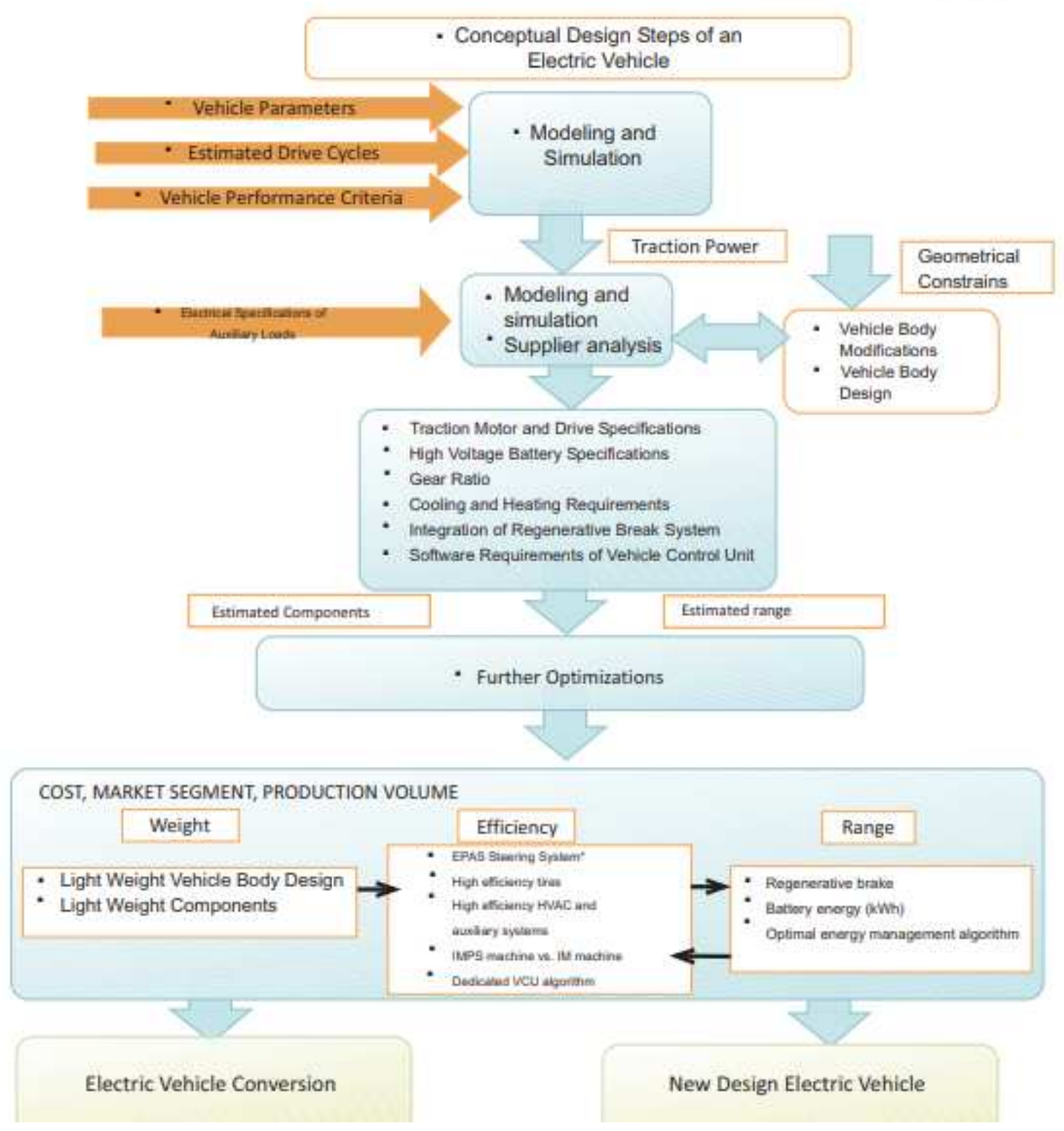

The needs for high output, long life, and minimizing the weight of automobiles drive train and machinery are constantly increasing, necessitating further increases in loads to gear and drive system parts like shafts. To meet this demand, further enhancement of the strengths of the individual parts of the vehicle like gears, shafts are required. In response to these demands, a variety of attempts have been made in two aspects such as new material development and process improvement. 
Li et al. [43] used pin-on-disc experiments to show that regular steel $(16 \mathrm{MnCr} 5)$ disks on powder metallurgy (PM) material pins, and PM material disks on PM material pins, had lower friction coefficients than regular steel disks on regular steel pins. On the basis of these results [44], investigated the gear mesh torque loss of regular steel gears and PM material gears. They found that running a standard material gear against a PM gear can improve the efficiency of transmission gears. Li et al. also investigated that the gear mesh torque loss of regular steel and PM material ground gears but the efficiency of super finished PM gear are unknown. The current technology shows little potential of gear weight reduction due to the trade-off between mass optimization and the manufacturing process.

ZHANG et al. [45] Discuss about demand for cleaner steels increases every year. In addition to lowering non-metallic oxide inclusions and controlling their morphology, composition and size distribution, clean steel requires lowering other residual impurity elements such as sulfur, phosphorus, hydrogen, nitrogen and even carbon, and trace elements such as $\mathrm{As}, \mathrm{Sn}, \mathrm{Sb}, \mathrm{Se}, \mathrm{Cu}, \mathrm{Pb}$, and $\mathrm{Bi}$.

Qi Zhang, et al [48] evaluates contact fatigue strength of the gear; for that motor speed of 1440 RPM was maintained at $1000 \mathrm{Nm}$. Load clutch is carried by front shaft which is used to apply the load. The flanges of the load clutch are twisted relative to each other and bolted together for applying load and torque was applied by weights and load lever.

\section{Results and Discussion:}

The results and discussion of this review papers will discuss in this chapter. Their results are different as they apply different methods and for different applications. Bernd Matthes [20] discuss the fuel efficiency of various power transmission types in terms of fuel saving and comfort rating. As it depicted in Fig. (5) Below, the best fuel economy transmission is AMT which is even better than manual transmission. In addition to the AMT, the wet DCTs and dry DCTs have the highest efficiency as well as good comfort. However, if passengers' comfort and driver's preference are considered, AMT is not the first option for conventional vehicles which only contain one power source. Based on the combined factors, the DCTs are the best choice for conventional vehicles.

Below figure shows the efficiency analysis and a comparison between different transmissions types. From the graph as clearly shown that the highest efficiency belongs to DCTs, especially the dry clutch DCT as stated in [49].

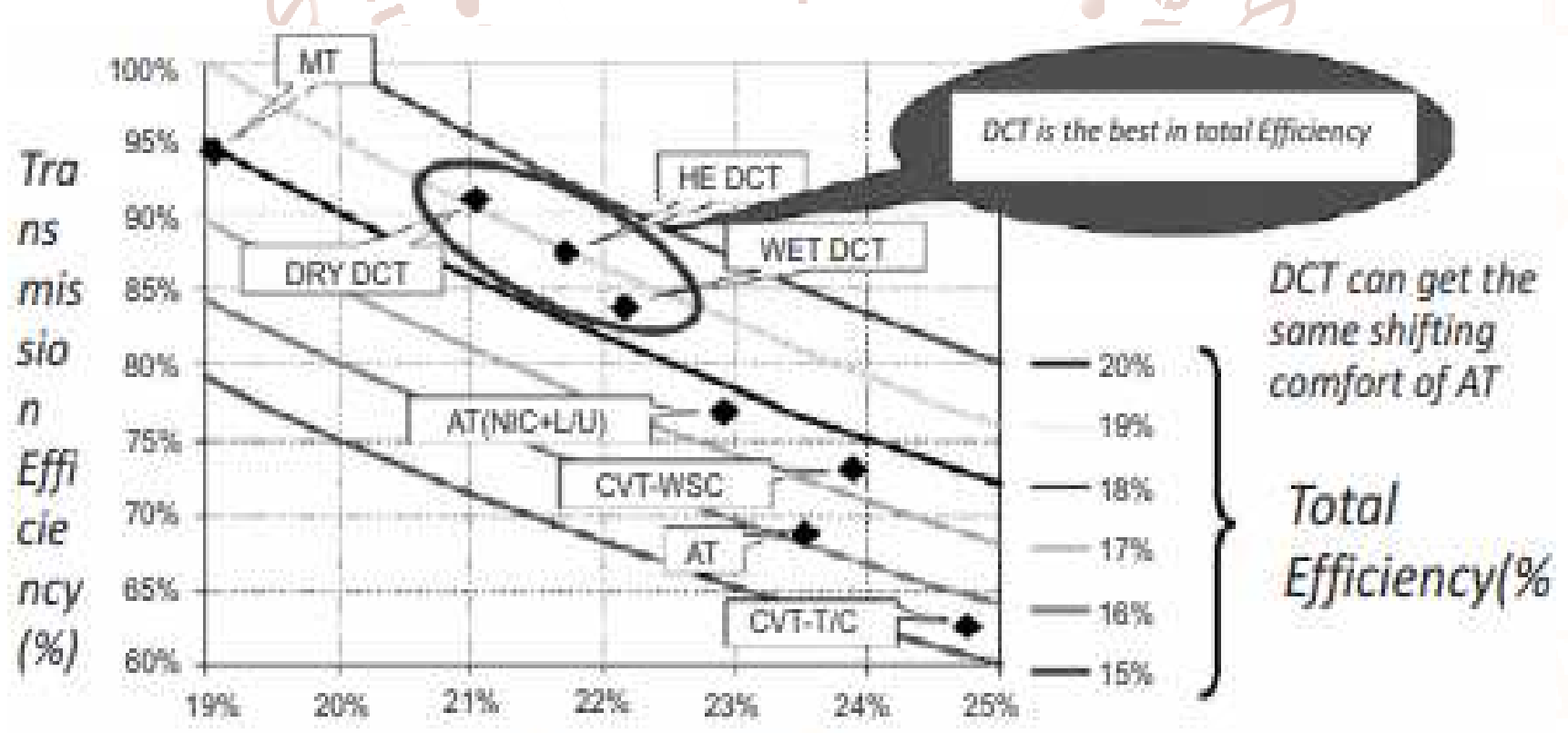

Engine Efficiency $(\%)$ 
International Journal of Trend in Scientific Research and Development (IJTSRD) ISSN: 2456-6470
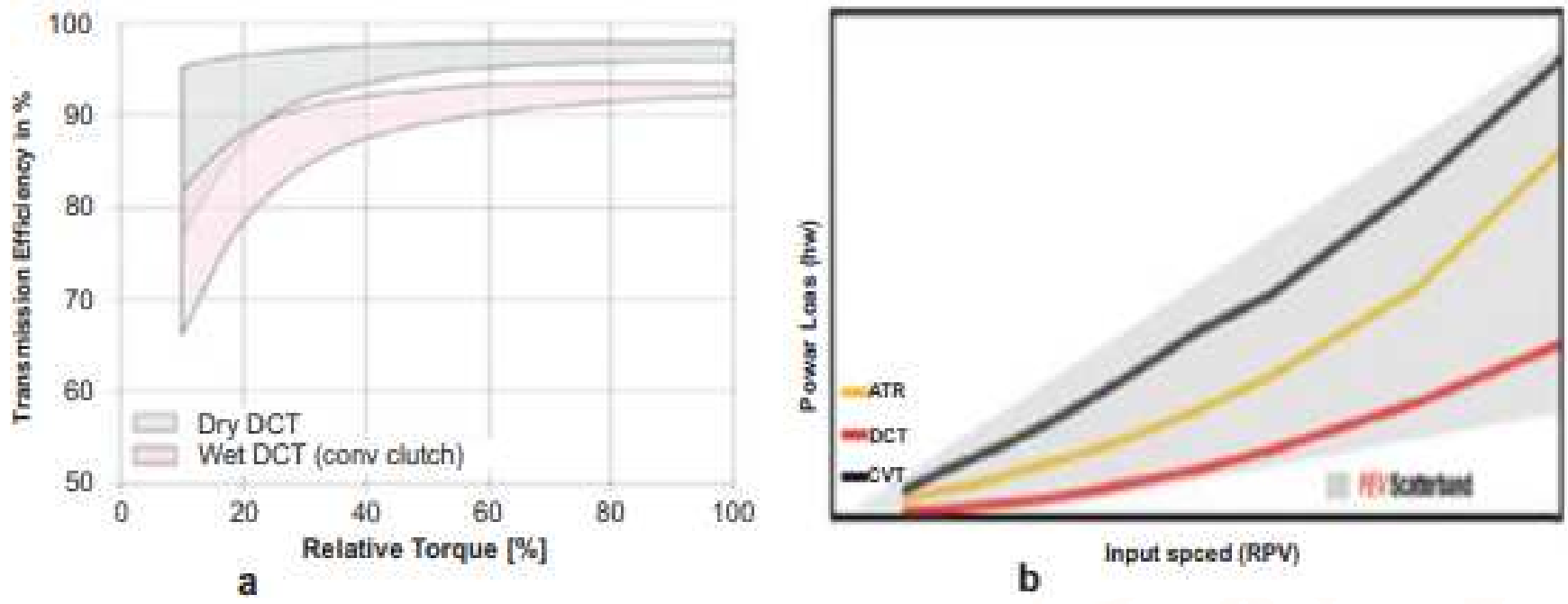

Below figure shows DCT Efficiency b/n Simulation and Test results with Input Torque $60 \mathrm{~N} \bullet \mathrm{m}$

(a) $1^{\text {st }}$ gear

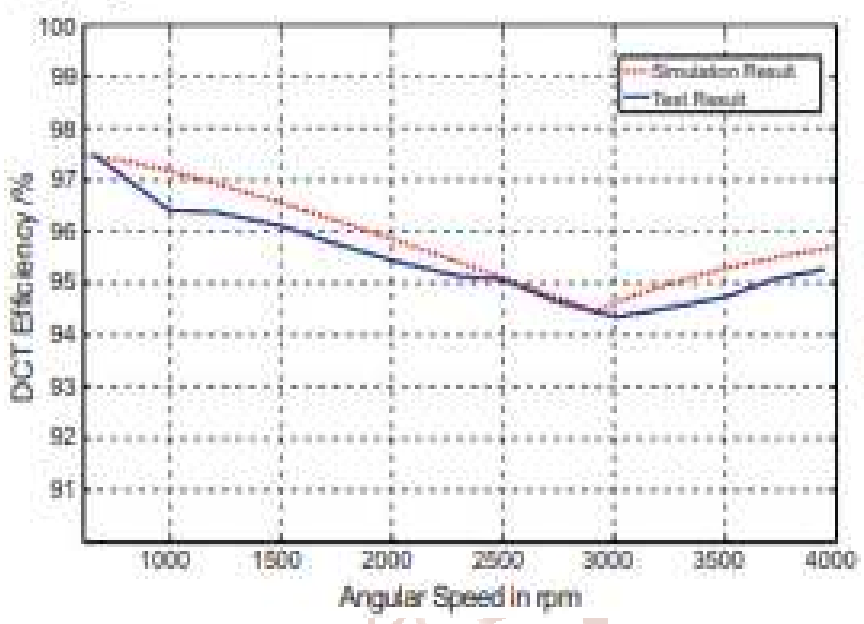

(b) $2^{\text {nd }}$ gear

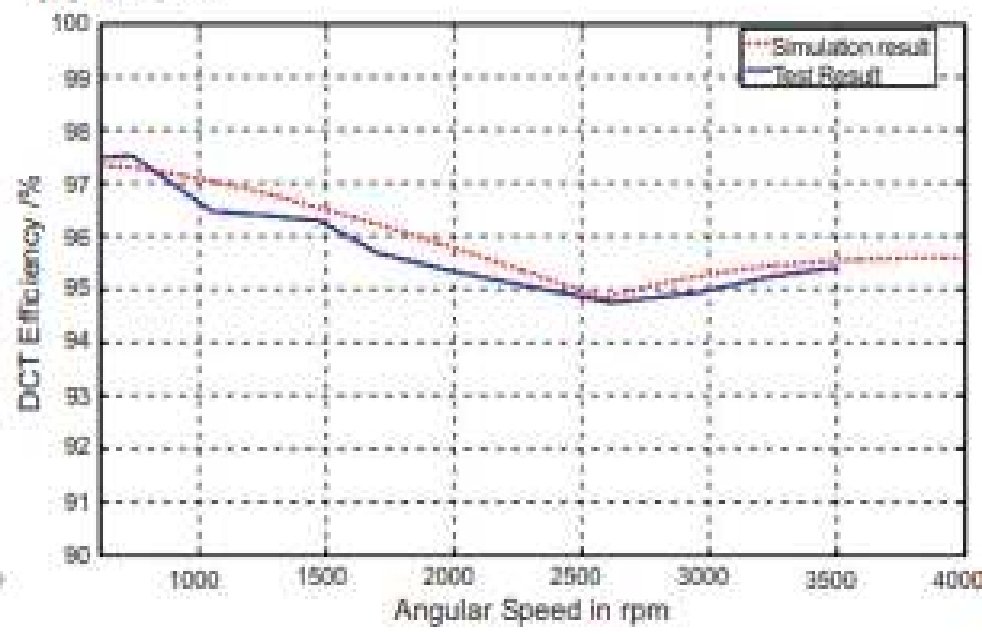

Comparison of Working is b/n Single Speed \& 2- Speed Transmission
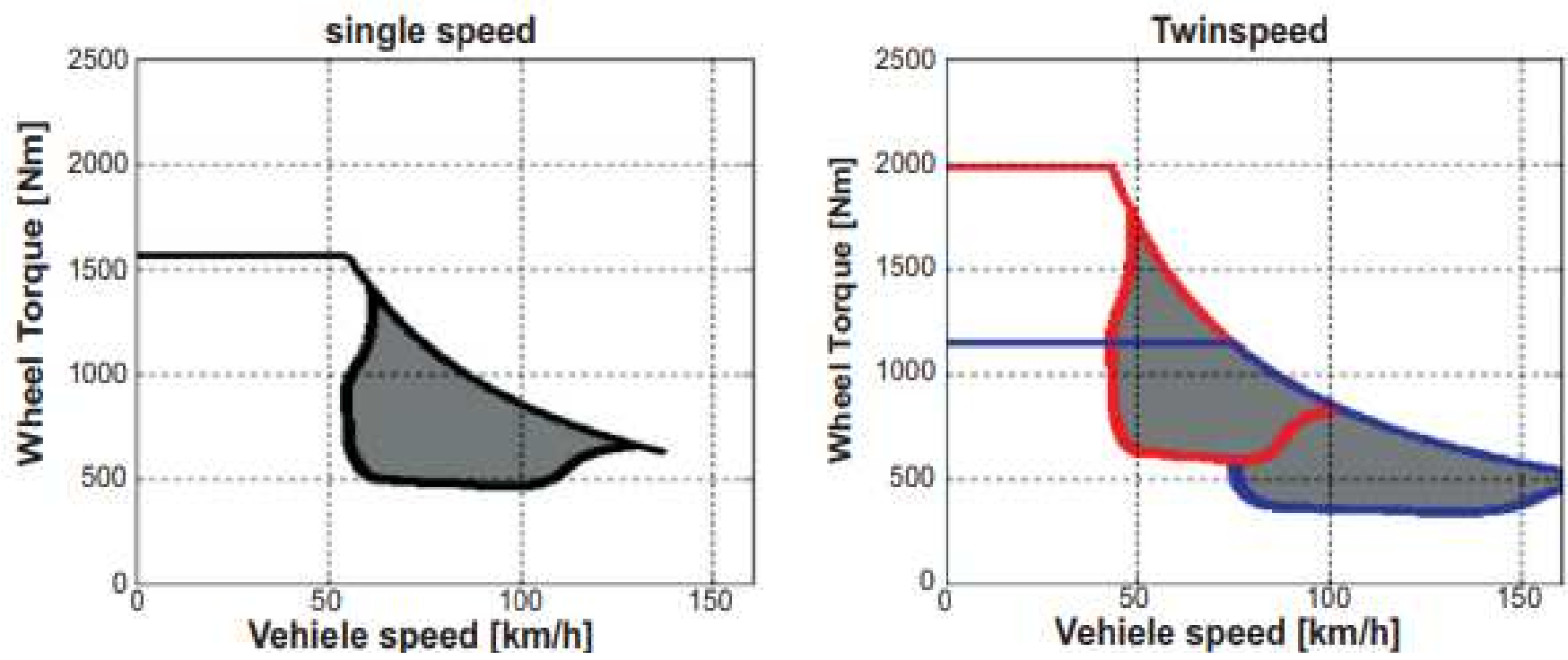

Upshift and Downshift of 2 Speed Transmissions 


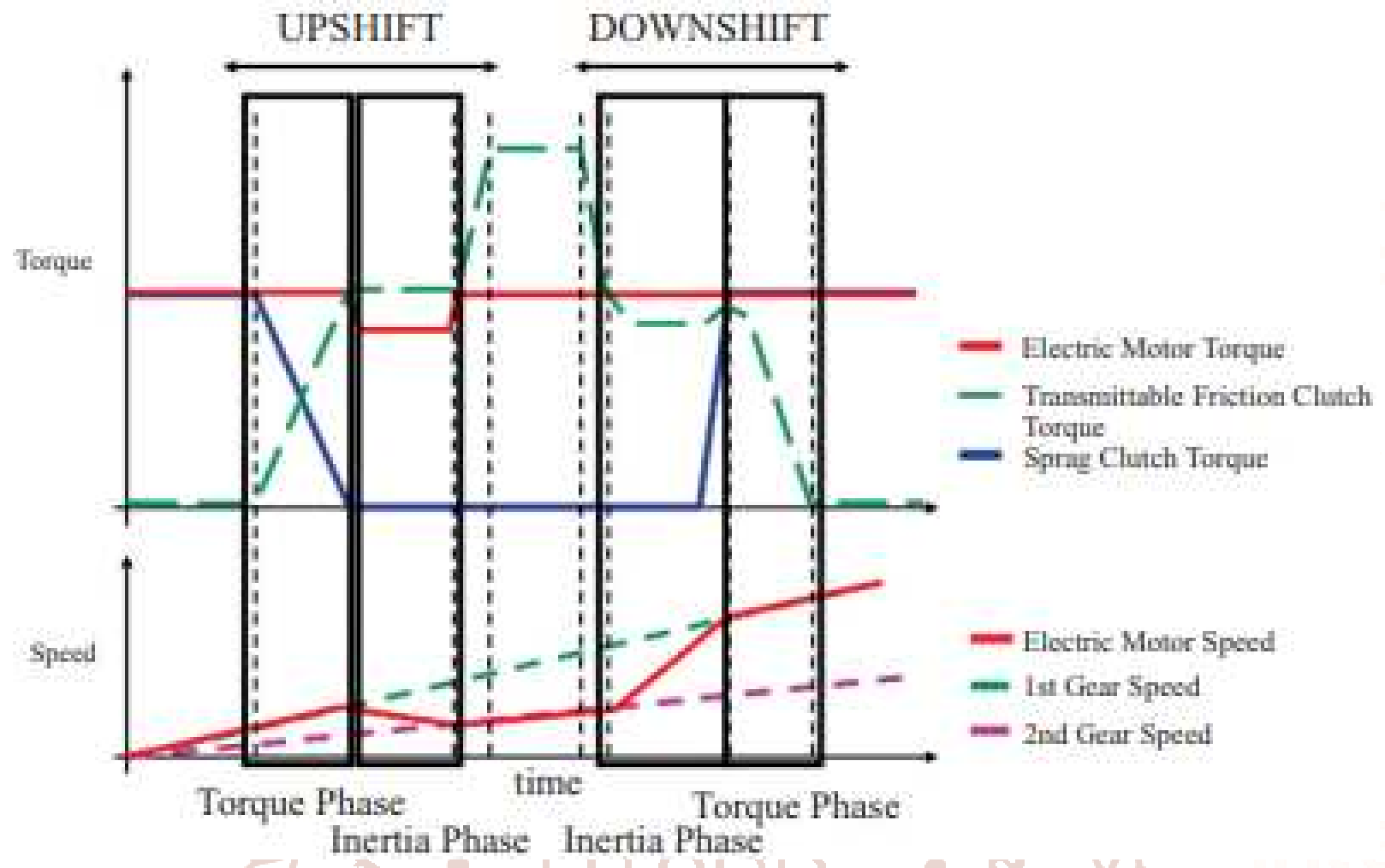

Comparison of d/t Gearbox for EV

\begin{tabular}{|c|c|c|c|c|c|}
\hline \multirow{2}{*}{$\begin{array}{c}\text { Type/ } \\
\text { layout }\end{array}$} & \multicolumn{2}{|c|}{ Baild length } & $\begin{array}{c}\text { 2 speed } \\
\text { Feasibility }\end{array}$ & Efficiency & Cost \\
\cline { 2 - 6 } & Transverse & Axial & & \\
\hline $\begin{array}{c}\text { Planetary } \\
\text { coaxial }\end{array}$ & $\oplus$ & & & & \\
\hline $\begin{array}{c}\text { Spur gearbox } \\
\text { coaxial }\end{array}$ & - & $\oplus$ & $\oplus$ & & \\
\hline $\begin{array}{c}\text { Planetary } \\
\text { parallel }\end{array}$ & $\oplus$ & & & & \\
\hline $\begin{array}{c}\text { Spur gearbox } \\
\text { coaxial }\end{array}$ & $\odot$ & $\oplus$ & $\oplus$ & $\oplus$ & $\oplus$ \\
\hline
\end{tabular}

Schematic Transmission Operation in first gear (left) and second gear (right)

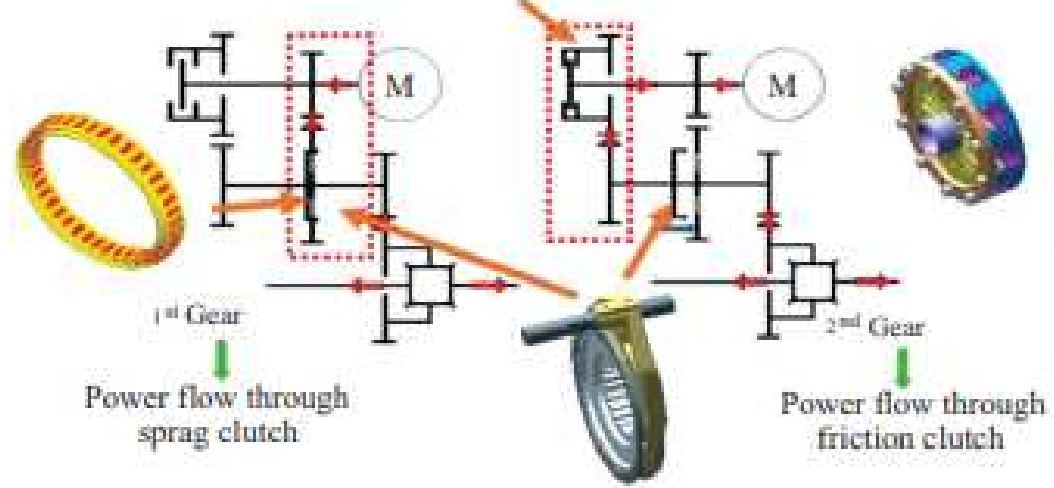

\section{Conclusion:}

The continuing demand for fuel economy improvements is forcing the automotive industry to reduce weight. The current trend towards lightweight design in automotive industry, also the weight of the transmissions has to be reduced. An optimization of the production process is necessary as well as the reduction of input material. Furthermore, reducing the weight and loss of transmission components can increase fuel efficiency and enhance greenness of vehicle. To minimize the drag torque the shifting time should minimize. Therefore, decreasing the gearshift time can enhance vehicle comfort this can be done with the help of actuators. 


\section{References:}

1. D. F. Brasil, Resolution no. 315, dated October 29, 2002. Provides for the new stage of the Vehicle Emission Control Program-PROCONVE, vol. 20. Daily Official of the Union, 2002.

2. J. Savoy, "Light-Weight Assembled Gears: A green design solution for passenger and commercial vehicles", Gear Technology, pp. 6471, 2013

3. P. D. Walker, A. R. Salisa, B. Zhu, and N. Zhang, "Modelling and optimisation of pure electric vehicle power trains: A comparison of single and two speed transmissions", Int. J. Vehicle Perform., vol. 2, pp. 85-102, 2015

4. M. Kulkarni, T. Shim, and Y. Zhang, "Shift dynamics and control of dual-clutch transmissions", Mech. Mach. Theory, vol. 42, pp. 168-182, 2007.

5. Y-S. Yoon, S. Kim, and K-S. Kim, "Conceptual design of economic hybrid vehicle system using clutch less geared smart transmission", Int. J. Automot. Technol., vol. 14, pp. 779-784, 2013.
6. F. Di Nicola, A. Sorniotti, T. Holdstock, F. Viotto, and S. Bertolotto, "Optimization of a multiplespeed transmission for downsizing the motor of a fully electric vehicle", SAE Int. J. Alternative Power trains, vol. 1, pp. 134-143, 2012.

7. C. C. Ming, and S. J. Cin, "Performance analysis of EV power train system with/without transmission", World Electric Vehicle J., vol. 4, p. 000629

8. M. Karamuk, M. E. Çepni, and S. Otan, "Electric vehicle power train development: Conceptual design and implementation", In: International conference on automotive and vehicle technologies, AVTECH: Istanbul, Turkey, 2013.

9. P. D. Walker, S. Abdul Rahman, B. Zhu, and N. Zhang, "Modelling, simulations, and optimisation of electric vehicles for analysis of transmission ratio selection", Adv. Mech. Eng., vol. 5, p. 340435, 2013.

10. B. Zhu, N. Zhang, P. Walker, W. Zhan, X. Zhou, and J. Ruan, "Two-speed DCT electric power train shifting control and rig testing", Adv. Mech. Eng., vol. 5, p. 323917, 2013. 